\title{
Impact of Friction Stir Welding (FSW) Process Parameters on Thermal Modeling and Heat Generation of Aluminum Alloy Joints
}

\author{
Saad B. Aziz ${ }^{1} \cdot$ Mohammad W. Dewan $^{1} \cdot$ Daniel J. Huggett ${ }^{1} \cdot$ Muhammad A. Wahab $^{1} \cdot$ Ayman M. Okeil $^{2} \cdot$ \\ T. Warren Liao ${ }^{1}$
}

Received: 1 April 2016/Revised: 21 April 2016/Published online: 19 July 2016

(C) The Chinese Society for Metals and Springer-Verlag Berlin Heidelberg 2016

\begin{abstract}
Friction stir welding (FSW) is a solid-state joining process, where joint properties largely depend on the amount of heat generation during the welding process. The objective of this paper was to develop a numerical thermomechanical model for FSW of aluminum-copper alloy AA2219 and analyze heat generation during the welding process. The thermomechanical model has been developed utilizing ANSYS ${ }^{\circledR}$ APDL. The model was verified by comparing simulated temperature profile of three different weld schedules (i.e., different combinations of weld parameters in real weld situations) from simulation with experimental results. Furthermore, the verified model was used to analyze the effect of different weld parameters on heat generation. Among all the weld parameters, the effect of rotational speed on heat generation is the highest.
\end{abstract}

KEY WORDS: Friction stir welding; Frictional dissipation energy; Temperature distribution; Friction modeling; Aluminum alloy

\section{Introduction}

Friction stir welding (FSW) is comparatively a new welding process invented by The Welding Institute in 1991 [1]. Since no melting or fusion occurs during the welding process, FSW is free of high heat input and solidification defects. Moreover, in the absence of filler material and fumes produced in the traditional fusion arc welding, the FSW process is not susceptible to defects caused by these

Available online at http://link.springer.com/journal/40195

Muhammad A. Wahab

wahab@me.lsu.edu

Saad B. Aziz

saziz1@1su.edu

1 Department of Mechanical and Industrial Engineering, Louisiana State University, Baton Rouge, LA 70803, USA

2 Department of Civil and Environmental Engineering, Louisiana State University, Baton Rouge, LA 70803, USA factors and is considered to be environmentally friendly. During the FSW process, a pin tool plunges while spinning into the joint between two parts that form the workpiece until the shoulder comes in contact with the workpiece as shown in Fig. 1. A backing plate is used to clamp the workpiece to prevent its movement while welding. The heat is generated due to friction between pin tool and workpiece and the plastic deformation of the workpiece material. After the local temperature of work material approaches its hot working temperature (i.e., $70 \%$ to $90 \%$ of melting temperature) and is soft enough to be stirred and displaced, the rotating tool is moved longitudinally along the welding line. This traverse motion of the pin tool causes the plasticized soft material at the leading edge of the rotating tool to be squeezed and sheared through a small slit formed by the displaced soft material at the side or lateral face of the tool, preferably in the direction of tool rotation. The displaced soft material is then deposited in the gap that forms at the trailing edge, left by rotating pin tool or probe. 


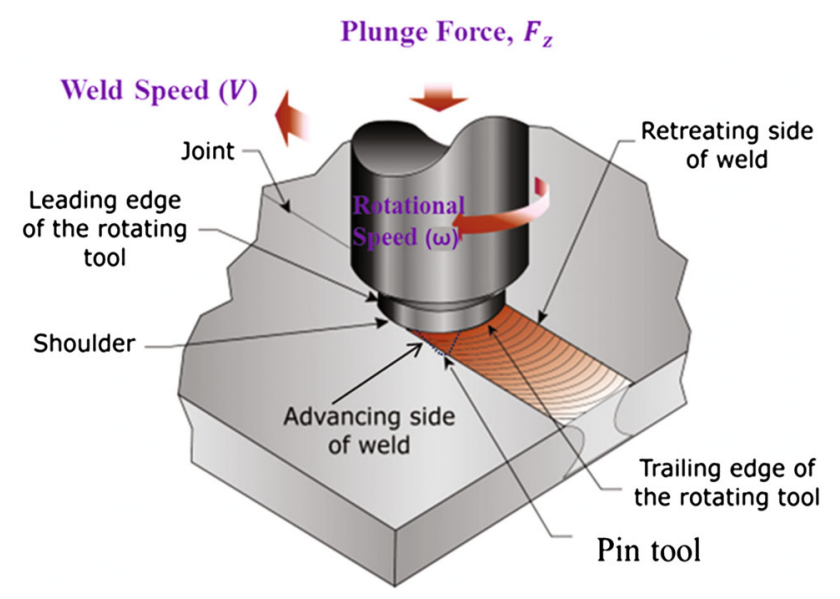

Fig. 1 Schematic of friction stir welding (FSW) process

Previous work on modeling FSW process can be divided into three main categories: pure analytical thermal models; finite element (FE)-based solid thermal and thermomechanical models, and computational fluid dynamics (CFD) models. Since the development of FSW process, numerous research articles have been published on thermal modeling of FSW [2-11]. Typically, the procedure involves applying a surface heat flux as the sole source heat. The heat source is then moved to simulate the advancing pin tool. Most models require "calibration" parameters. To overcome this problem, Schmidt and Hattel [12] have proposed a thermal model, where heat generation is considered as surface heat flux from the tool shoulder, which is dependent on the tool's radius and temperature-dependent yield stress. This type of model, which is often named as "thermal pseudomechanical model" as the temperature generation, is expressed as temperature-dependent yield stress by taking mechanical effects into account. Schmidt et al. [13] have developed another model, which employs a linear weighting of the contribution from sticking and sliding in terms of contact state variable, $\delta$.

Song and Kovacevic [14] developed a thermomechanical model considering heat generated between tool and workpiece. However, the authors considered heat generation of the pin tool as a moving heat source, not as a heat generated through process itself. In another study, Chen and Kovacevic [15] developed a Lagrangian thermomechanical model, which incorporated temperature and multilinear strain-hardening effect. The temperature effect in the model has been developed by considering tool thermal effect as a moving heat source. Also the effect of the moving heat source on the workpiece material and the effect of various weld parameters on residual stress have been studied. However, no contact surface between the tool and the workpiece, and in-between the plates has been considered.
A transient analytical thermal model of FSW has been proposed by Zhang et al. [16] considering all steps in FSW. The heat generation rate was modeled using a temperaturedependent friction coefficient, which was modeled by the inverse solution method (ISM). An extension work of the model is proposed by Zhang et al. [17] to study the effect of various weld conditions on heat generation and temperature. A continuum-based thermomechanical model was developed by Buffa et al. [18], in which the workpiece material was modeled as rigid visco-plastic and rate-dependent material. Temperatures obtained from the model were found to be in good agreement with experimental work. However, the authors have considered material property for thermal conductivity and thermal capacity to be constant, which is known to vary with the temperature. Furthermore, the workpiece was considered as a "single block" to avoid contact instabilities.

Zhang and Zhang [19] developed a rate-independent model based on arbitrary Lagrangian-Eulerian (ALE) formulation to study the effect of plunge force on material flow during FSW. The effect of stick (material has the same local velocity as the tool) and slip (the velocity maybe lower) during FSW has been modeled assuming slip rate of $0.5 \%$ (Slip rate $\left.=\frac{\text { Angular rotation speed of the contact matrix layer }}{\text { Angular rotation speed of the tool }}\right)$. The authors concluded that with the increase in plunge force, both friction and plastic energy increased. However in their research, the authors did not include any analysis of temperature distribution during FSW. Moreover, the friction coefficient was considered to remain constant, whereas in real life, the friction coefficient is temperature dependent. Using the same material model, Zhang and Zhang [20] studied the effect of travel speed on material flow during FSW. Nevertheless, heat generated during FSW was not considered in this work as well. In another study, Zhang et al. [21] developed a rate-independent material model using ALE formulation. The stick and slip effect during FSW has been modeled by using modified Coulomb's law. The authors studied the effect of material flow on weld parameters, i.e., plunge force, rotational speed, and travel speed. However, in their research, heat generation was not modeled as a process by itself; rather they used experimental temperature curve as an input in the model.

The objective of this work is to develop a model to estimate heat generation due to friction during FSW. One major difference comparing the present model with previous models published in the literature is that a temperaturedependent friction coefficient is employed that takes into account both sticking and sliding friction conditions along with a rate-independent plasticity model. Second, heat generation as a process in itself is modeled by accounting for frictional heat between tool/boundary conditions. To demonstrate the validity of the model, the model is applied 
to three different weld schedules of aluminum AA2219 alloys. Finally, a parametric study was conducted on critical weld parameters including plunge force, rotational speed, and travel speed. The plunge force was varied from $12.45 \mathrm{kN}$ to $23.35 \mathrm{kN}$ to cover a wide range of weld scenarios. Similarly, the rotational speed was varied from $200 \mathrm{rpm}$ to $450 \mathrm{rpm}$, and the travel speed ranging from $1.693 \mathrm{~mm} / \mathrm{s}$ to $3.386 \mathrm{~mm} / \mathrm{s}$ was considered. These weld schedules have been selected from the experiment.

\section{Model Description}

Joining aluminum alloy by FSW has been a great interest for research nowadays [22-25]. The finite element model presented in this paper was used to simulate an FSW process of workpiece that the authors tested [26]. The welds were made with a fixed pin tool on I-STIR PDS FSW machines. The experimental setup for this workpiece is shown in Fig. 2. The workpiece material is AA2219 aluminum alloy, whose chemical composition is listed in Table 1. A taper threaded pin along with a tool made of H13 steel is used for FSW. The radius of the tool shoulder is $15.27 \mathrm{~mm}$, and the height of the shoulder is $38.1 \mathrm{~mm}$. The tapered angle of the tool is $10^{\circ}$. Two chill bars have been placed on top of the workpiece to help clamp it. In the model, the tool is considered as a rigid solid and the workpiece is considered as a ductile material, whose constitutive model is capable of simulating elastic, plastic, large strain, large deformation, and isotropic hardening effect. A 3D 20-node coupled-field solid element was selected to model both the workpiece and the tool in ANSYS $^{\circledR}$. By studying the speed of the FSW schedules covered in this research, the plate's elastic and plastic behavior was assumed to be rate independent. As stated

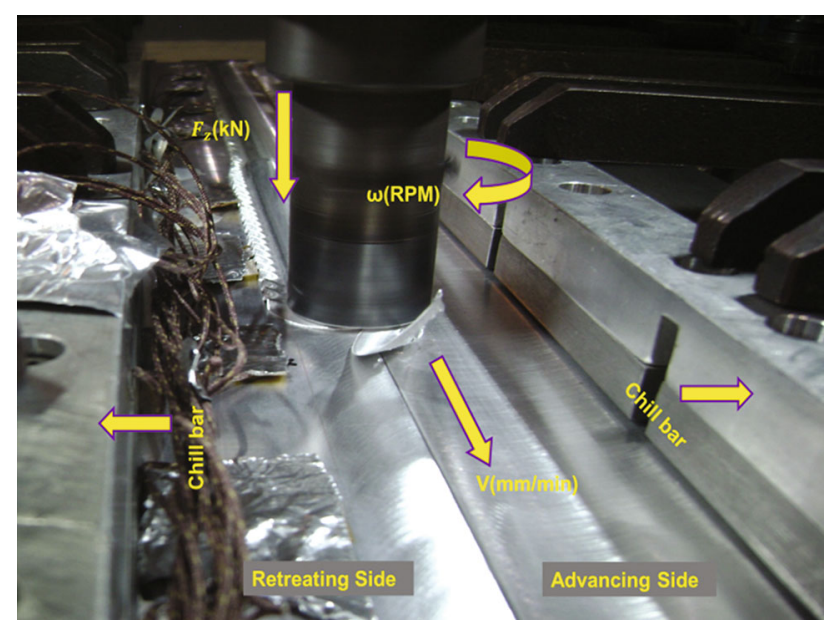

Fig. 2 Experimental setup and process parameter of FSW $\left(F_{z}=\right.$ plunge force, $\omega=$ rotational speed, $V=$ travel speed)
Table 1 Chemical composition of the workpiece (AA2219)

\begin{tabular}{lllllllll}
\hline $\mathrm{Si}$ & $\mathrm{Fe}$ & $\mathrm{Cu}$ & $\mathrm{Mn}$ & $\mathrm{Mg}$ & $\mathrm{V}$ & $\mathrm{Zn}$ & $\mathrm{Ti}$ & $\mathrm{Zr}$ \\
\hline 0.20 & 0.30 & 6.8 & 0.40 & 0.02 & 0.15 & 0.10 & 0.10 & 0.25 \\
\hline
\end{tabular}

earlier, there was no heat source input in this work; rather, heat generation in the model was a result of friction work between the tool and the workpiece interface. The meshed model has 7014 nodes and 6921 elements as shown in Fig. 3.

\subsection{Material and Associated Flow Model}

As stated earlier, the FSW model presented in this paper used a rate-independent plasticity material, where three distinct criteria have been used to determine rate-independent plasticity model and these are: (a) flow rule, (b) hardening rule, and (c) yield criterion.

Flow rule determines the increment in plastic strain from the increment in load. In the current analysis, associative flow rule is used, which is represented by Eq. (1):

$\left\{\mathrm{d} \varepsilon^{\mathrm{pl}}\right\}=\mathrm{d} \lambda\left\{\frac{\partial \mathrm{G}}{\partial \sigma}\right\}$.

where $\mathrm{d} \varepsilon^{\mathrm{pl}}=$ change in plastic strain, $\mathrm{d} \lambda=$ magnitude of the plastic strain increment, $\mathrm{G}=$ plastic potential (which determines the direction of plastic straining), and ว $\sigma=$ change in stress.

The von Mises yield criterion has been applied in the current analysis as a yield criterion. The von Mises yield criterion is represented by Eq. (2) [27]:

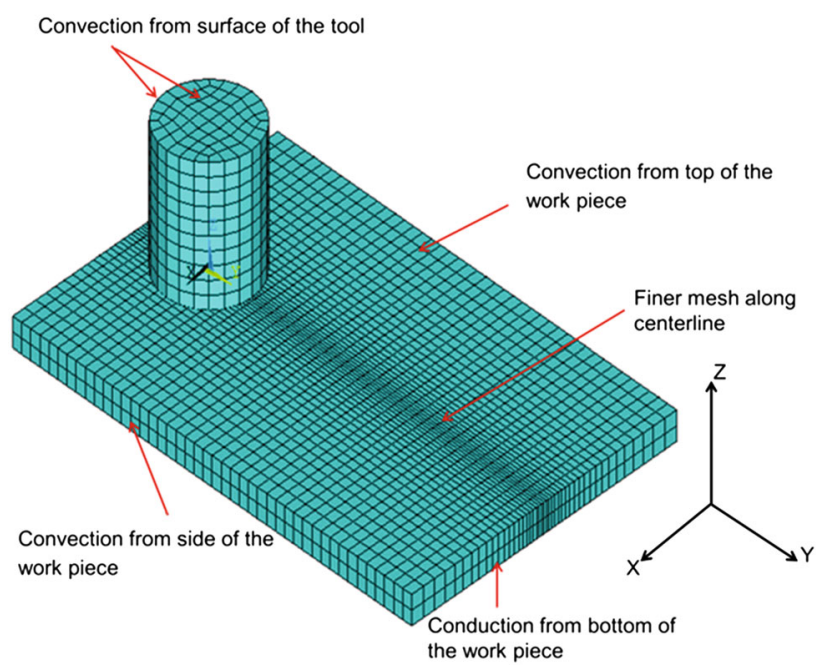

Fig. 3 Meshes and thermal boundary conditions of the finite element model 
$f\left(\sigma, \sigma_{\mathrm{y}}\right)=\sigma_{\mathrm{e}}-\sigma_{\mathrm{y}}=0$.

where

$\sigma_{\mathrm{e}}=$ von Mises effective stress

$$
=\sqrt{\frac{3}{2}\left(\sigma: \sigma-\frac{1}{3} \operatorname{tr}(\sigma)^{2}\right)},
$$

$\sigma_{\mathrm{y}}=$ yield strength and $\operatorname{tr}=$ Tresca criterion

The total amount of plastic work is the sum of the plastic work done over the history of loading as expressed by Eq. (4):

$\chi=\int\{\sigma\}^{T}[M]\left\{d \varepsilon^{\mathrm{pl}}\right\}$.

where $\chi=$ plastic work, $[M]=$ mass matrix, and $\sigma=$ Cauchy stress tensor.

The amount of frictional work has been calculated by Eq. (5) [27];

$\mathcal{R}=\tau \times \gamma$.

where $\mathcal{R}=$ frictional work, $\tau=$ equivalent frictional stress, and $\gamma=$ sliding rate.

\subsection{Contact Condition}

The critical part in numerical modeling of FSW is simulating the contact condition between various parts, i.e., workpiece, pin tool, and shoulder [28]. In this research, modified Coulomb's law is applied to describe the friction force between the tool and the workpiece.

During sticking condition, the matrix close to the tool surface sticks to it. Shearing is considered to address the velocity difference between the layer of the stationary material points and the material moving with the tool. The shear yield stress, $\tau_{\text {yield }}$, is taken as

$\tau_{\text {yield }}=\frac{\sigma_{\mathrm{y}}}{\sqrt{3}}$.

where $\sigma_{\mathrm{y}}=$ yield strength of the material.

In the presented model, the contact shear stress was taken equal to the shear yield stress, which depends on the temperature:

$\tau_{\text {contact }}=\tau_{\text {yield }}=\frac{\sigma_{\mathrm{y}}}{\sqrt{3}}$.

During sliding condition, the tool surface and the workpiece material slide with respect to each other. Using Coulomb's friction law, the shear stress necessary for sliding is:

$\tau_{\text {contact }}=\tau_{\text {friction }}=\mu p=\mu \sigma$.

where $p$ is the contact normal pressure, $\mu$ is the friction coefficient, and $\sigma$ is the contact stress.
A value of $\tau_{\max }=\frac{\sigma_{y}}{\sqrt{3}}=0.58_{y}$ (distortion energy criterion) is applied to determine stick/slip condition in the current analysis.

In the current analysis, according to the modified Coulomb's model, when the contact shear stress, $\tau_{\text {contact }}$, is less than the maximum frictional stress, $\tau_{\max }$, a sticking condition is modeled. Conversely, when the contact shear stress, $\tau_{\text {contact }}$, exceeds $\tau_{\max }$, the contact and the target surface will slide relative to each other, (i.e., sliding condition is modeled). The conditions of contact shear stress vs contact pressure for sticking and sliding are described in Fig. 4.

$\tau_{\text {contact }} \leq \tau_{\max } \rightarrow($ Sticking $) ; \tau_{\text {contact }} \geq \tau_{\max } \rightarrow$ (Sliding).

A value of $\tau_{\max }=\frac{\sigma_{\mathrm{y}}}{\sqrt{3}}=0.58 \sigma_{\mathrm{y}}$ (distortion energy criterion) is used in the current analysis, where $\sigma_{\mathrm{y}}=$ yield strength of the material. Since the material yield strength is highly temperature dependent, temperature-dependent yield strength value of AA2219 has been used in the current analysis.

\subsection{Thermal Boundary Condition}

The initial boundary condition used for the calculation in the model can be expressed as Eq. (10) follows:

$T(x, y, z, t)=T_{0}$.

where $T(x, y, z, t)$ represents the transient temperature field $T$, which is a function of time and the spatial coordinates $(x, y, z)$, and $T_{0}$ represents the initial temperature.

The governing equation describing transient heat transfer process during FSW process can be described by the Eq. (11)

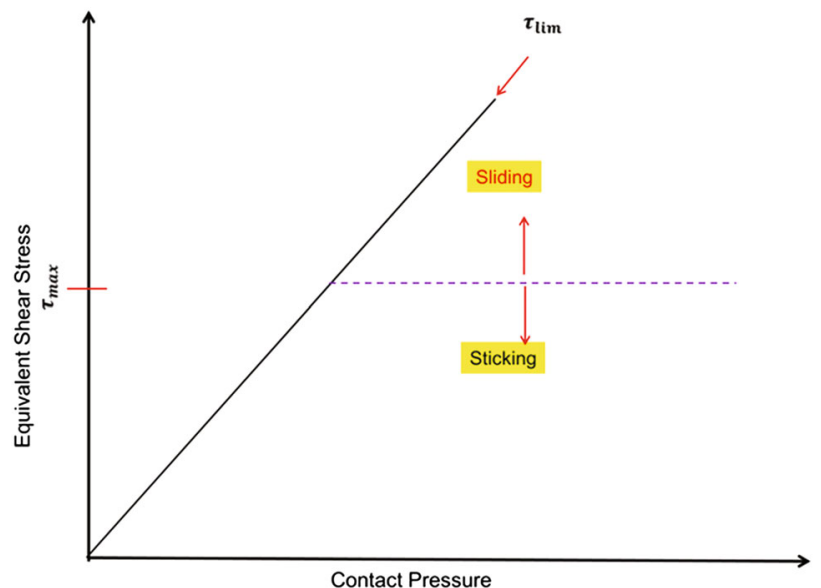

Fig. 4 Modified Coulomb's law depicting sliding and sticking conditions 
$\rho c_{\mathrm{p}} \frac{\partial T}{\partial t}=k\left(\frac{\partial^{2} T}{\partial x^{2}}+\frac{\partial^{2} T}{\partial y^{2}}+\frac{\partial^{2} T}{\partial z^{2}}\right)+Q$.

where $Q$ is the heat generation, $c_{\mathrm{p}}$ is the specific mass heat capacity, $\rho$ is the density of the material, $k$ is the thermal conductivity, and $T$ is the absolute temperature.

In finite element formulation, Eq. (11) can be represented by Eq. (12):

$C(t) \dot{T}+K(t) T=Q(t)$.

where $C(t)$ is the time-dependent capacitance matrix, $T$ is the nodal temperature vector, $\dot{T}$ is the temperature derivative with respect to time (i.e., $\left.\frac{\mathrm{d} T}{\mathrm{~d} t}\right), K(t)$ is the timedependent conductivity matrix, and $Q(t)$ is the time-dependent heat vector.

It is assumed that convection from the free surfaces, as can be seen in Fig. 3, is the main reason for heat loss in the workpiece. The heat loss from both the side and the top surfaces is calculated using Eq. (13):

$q_{1}=h_{\mathrm{con}}\left(T-T_{\mathrm{o}}\right)$.

where $T$ represents the absolute temperature of the workpiece, $T_{\mathrm{o}}$ ambient temperature and $h_{\text {con }}$ convection coefficient. The experimental setup that is being modeled here has a chill bar present at the top surface of the weld plate, which helps to clamp the workpiece, and also the chill bar acts as a heat sink. This will cause a high heat transfer coefficient from the top surface, which has been given a value of $100 \mathrm{~W} / \mathrm{m}^{2}$. From the side surface, heat transfer of $30 \mathrm{~W} / \mathrm{m}^{2}$ has been used for aluminum to air convection. At the bottom, a backing plate is placed to oppose the downward plunge force. This backing plate also acts as a high heat sink absorbing heat rapidly during welding; consequently, a high heat transfer coefficient is used to model the heat transfer from backing plate. The heat loss from backing plate is modeled by Eq. (14):

$q_{\mathrm{b}}=h_{\mathrm{b}}\left(T-T_{\mathrm{o}}\right)$.

where $h_{\mathrm{b}}$ represents the convection heat coefficient from backing plate. Due to the complexity associated with determining contact conditions between the workpiece and the backing plate, the value of $h_{\mathrm{b}}$ was calibrated to match experimental data, which was found to be $300 \mathrm{~W} / \mathrm{m}^{2}$. Heat loss from tool surface was calculated using Eq. (15):

$q_{\mathrm{w}}=h_{\mathrm{w}}\left(T-T_{\mathrm{o}}\right)$.

where $h_{\mathrm{w}}$ represents the convection heat coefficient from the pin tool. A value of $30 \mathrm{~W} / \mathrm{m}^{2}$ has been used as heat transfer coefficient from tool surface in the present model, which is calibrated to best fit the experimental data. All other thermal boundary conditions of current analysis are shown in Fig. 3.

\subsection{Mechanical Boundary condition}

Displacement boundary conditions were introduced to the model to match the actual welding conditions. The boundary condition was specified as complete displacement restraint, where the workpiece was clamped:

$U=0$.

Other parts of the workpiece, where the workpiece was supported on the backing plate, were assumed to be restrained in the normal direction:

$U_{Z}=0$.

The mechanical boundary conditions used in the current analysis are shown in Fig. 5.

\section{FSW Calibration Experiments}

Experimental results from two welding AA2219 aluminum alloy plates have been used for model calibration. The workpiece length was $609.6 \mathrm{~mm}$, its width $152.4 \mathrm{~mm}$ and its thickness $8.128 \mathrm{~mm}$. The pin tool used in this study is made of $\mathrm{H} 13$ tool steel. The radius of the tool shoulder is $15.27 \mathrm{~mm}$, and the height of the shoulder (tool shank height) is $38.1 \mathrm{~mm}$. The pin tool is made of MP159 nickelcobalt-based multiphase alloy. The pin radius at the top is $4.78 \mathrm{~mm}$ and the height of the pin tool is $7.9 \mathrm{~mm}$. The tapered angle of the tool is $10^{\circ}$. Temperatures were measured during welding from the surface of the workpiece by both K-type thermocouple and FLIR thermovision A40 thermographer. The layouts of the thermocouples are shown in Fig. 6.

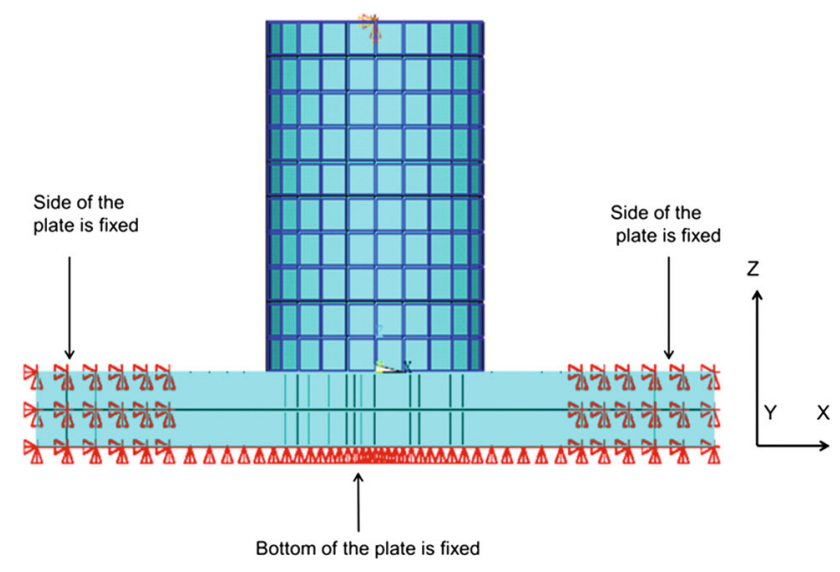

Fig. 5 Mechanical boundary conditions of the plate 


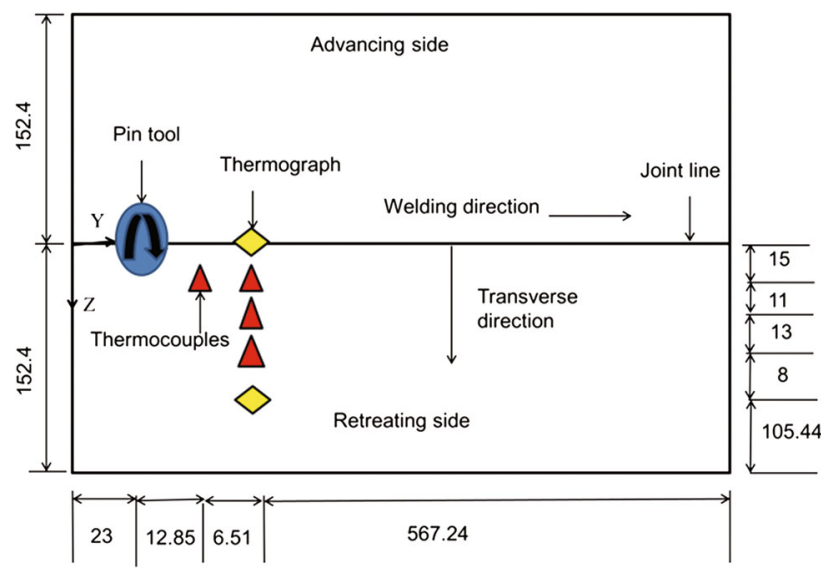

Fig. 6 Layouts of the thermocouples (embedded in the surface) and thermographer (all dimensions are in millimeter)

\section{FEA Modeling}

\subsection{Workpiece and Tool Modeling}

Finite element analysis software, ANSYS ${ }^{\circledR}$, has been used to carry out the numerical simulation. The FSW modeling is divided into three stages, namely (1) plunge, (2) dwell, and (3) traverse stages. During the plunge stage, the pin tool first moves down vertically and then starts rotating during the dwell stage followed by moving along the weld seam with rotation during the traverse stage. In order to avoid complexity during the initial plunge stage, heat generation was only considered during the dwell and the traverse stages. Details of the modeling steps, i.e., duration and the boundary conditions, are listed in Table 2 .

It should be noted that the traverse step, which is the longest step at $30 \mathrm{~s}$, was used for thermal verification by comparing thermocouple data with FEA model.

In the current simulation, a Lagrangian model has been adopted to incorporate temperature and multilinear isotropic strain hardening with large strain capability and material deformation behavior. A 3-D 20-node coupledfield SOLID226 element, as shown in Fig. 7, was used to model both the plate and the tool. The SOLID226 element

Table 2 Simulation details for three steps

\begin{tabular}{lll}
\hline Stage & Time step $(\mathrm{s})$ & Pin tool boundary condition \\
\hline Plunging & 1 & Displacement along $z$-axis \\
Dwelling & 10 & Rotation along $z$-axis \\
Traversing & 16 & Rotation along $z$-axis \\
& & Movement along $y$-axis \\
\hline
\end{tabular}
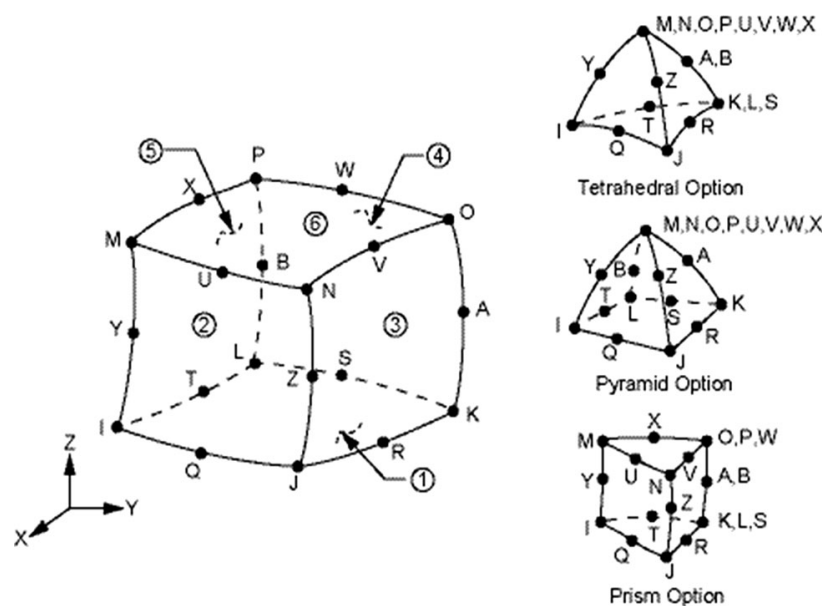

Fig. 7 Solid226 elements [27]

was selected because of its plasticity, stress stiffening, large deflection and large strain capabilities [27].

Two rectangular plates were created in the model simulating the two welded parts of the workpiece. In order to reduce simulation time, the length and width of the plate have been reduced, but the actual thickness was maintained. Thus, the simulation captured the behavior of the steady-state portion of the FSW process effectively without the need to simulate the entire steady-state region. The plate width was reduced in such a way that the regions away from the weld line are not affected by the welding process. The dimension of the modeled plates is $152.4 \mathrm{~mm}$ $(\mathrm{L}) \times 47.625 \mathrm{~mm}(\mathrm{~W}) \times 8.128 \mathrm{~mm}(\mathrm{~T})$. To improve the fidelity of the results around the weld seam, the centerline of the plate was modeled with a finer mesh as shown in Fig. 3.

The tool shank had a height of $38.1 \mathrm{~mm}$ and shoulder radius of $15.27 \mathrm{~mm}$, which is identical to the dimensions used during FSW modeling. During the FSW process, heat is mainly generated from friction between the tool and the workpiece. For this purpose, a surface to surface contact pair was used between the tool and workpiece as shown in Fig. 11. The rate of frictional dissipation is calculated by Eq. (18)

$q=$ FHTG $\times \tau \times \gamma$.

where $\mathrm{FHTG}=$ fraction of frictional energy converted to heat.

In the model, $100 \%$ of frictional energy is considered converted into the heat energy.

The amount of frictional dissipation on contact and target surface is expressed by Eqs. (19) and (20).

$q_{\mathrm{c}}=\mathrm{FWGT} \times \mathrm{FHTG} \times \tau \times \gamma$.

$q_{\mathrm{T}}=(1-\mathrm{FWGT}) \times \mathrm{FHTG} \times \tau \times \gamma$. 
where $q_{\mathrm{c}}=$ contact side, $q_{\mathrm{T}}=$ target side, and FWGT $=$ weight factor of the distribution of heat between the contact and target surfaces.

Also in the current simulation, $95 \%$ of the generated heat was distributed in the workpiece and $5 \%$ of the generated heat was distributed in the pin tool following recommendations by previous research work [29]. Heat transfer from the tool to the workpiece was minimized by assigning a low conductance value of $10 \mathrm{~W} /\left(\mathrm{m}^{2}{ }^{\circ} \mathrm{C}\right)$ between the tool and workpiece.

The friction coefficient plays a great role in generating heat during FSW. However, the friction coefficient in FSW is dependent upon many factors, such as temperature, contact geometry, relative motion between tool and workpiece and applied force. Zhang et al. [16] have done an extensive study on the above-mentioned parameters and found out that the friction coefficient is mainly temperature dependent. Therefore, a temperature-dependent friction coefficient has been used in the current model varying between 0.4 and 0.25 [30] and has been listed in Table 3 . From Table 3, we can see that as temperature rises, friction coefficient remains constant up to $200{ }^{\circ} \mathrm{C}$; after $200{ }^{\circ} \mathrm{C}$, friction coefficient starts decreasing. The choice of this friction coefficient can be described as explained by the work of Zhang et al. [16] as shown in Fig. 8.

Two contact element types CONTA174 and TARGE170 were used to model the contact between two plates as shown in Fig. 9. Between the two workpieces, a high thermal contact conductance $2 \times 10^{6} \mathrm{~W} /\left(\mathrm{m}^{2}{ }^{\circ} \mathrm{C}\right)$ was introduced to develop an almost perfect thermal contact. In general, the maximum temperature generated during welding is about $0.7-0.9$ of the melting temperature of the material [31]. When the temperature rises over 0.7 of the melting temperature (melting temperature of AA2219 is $543{ }^{\circ} \mathrm{C}$ ), both plates will be joined and remain joined even after the temperature is decreased. In this current simulation, $400{ }^{\circ} \mathrm{C}$ is set as a temperature for joining. A master node/pilot node is created at the top of the tool to control the rotating and traverse speed of the pin tool as shown in Fig. 9. Also in the current model, the amount of plastic

Table 3 Temperature-dependent friction coefficient used in the model

\begin{tabular}{ll}
\hline Temperature $\left({ }^{\circ} \mathrm{C}\right)$ & Friction coefficient \\
\hline 25 & 0.4 \\
100 & 0.4 \\
200 & 0.4 \\
300 & 0.35 \\
400 & 0.25 \\
420 & 0.25 \\
543 & 0.01 \\
\hline
\end{tabular}

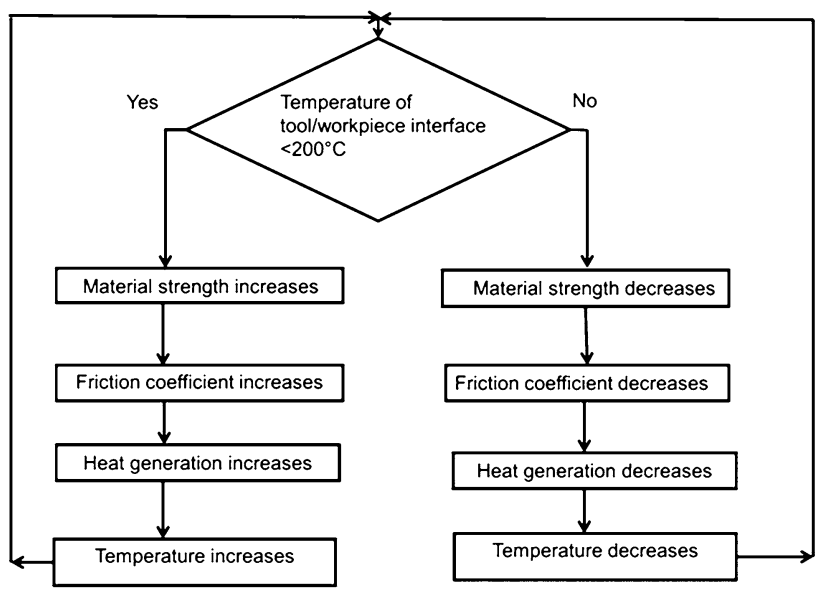

Fig. 8 Flowchart for choice of friction coefficient

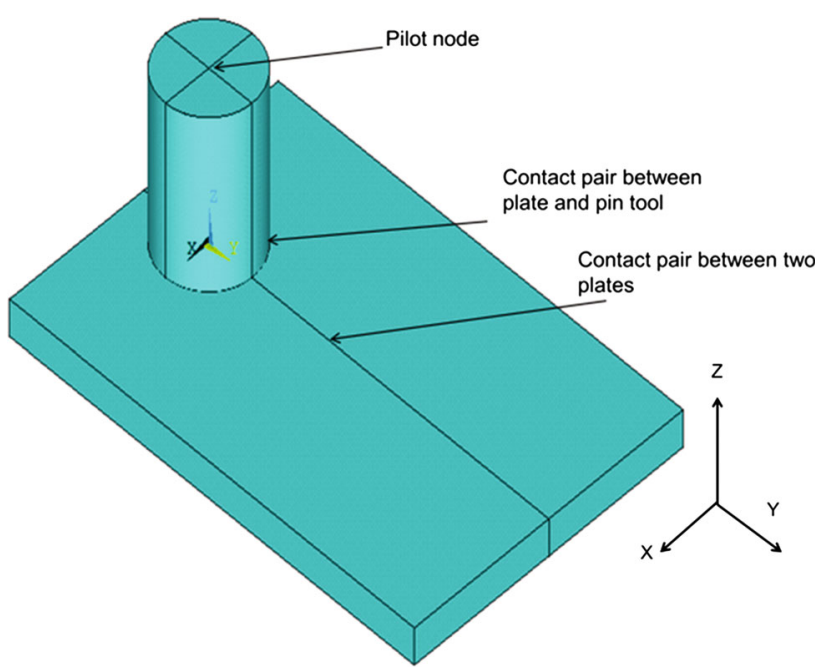

Fig. 9 Contact pair between tool and workpiece and between two plates

work converted to heat is considered to be $80 \%$, which has been found by the previous research work [29]. It should be noted that some researchers estimated the heat generated from plastic work to be minimal (less than 5\%) compared to that generated by friction [32]. From Eq. (4), total plastic work converted to heat can be expressed by Eq. (21).

$q_{\mathrm{p}}=0.8 \times \chi=0.8 \times \int_{0}^{t}\{\sigma\}^{T}[M]\left\{\mathrm{d} \varepsilon^{\mathrm{pl}}\right\}$.

To account for large strain and large deformation, ANSYS $^{\circledR}$ command NLGEOM,on is used in the current analysis [33]. During FSW, material properties are considered to be temperature dependent since the temperature gradient is large. The solution time step size was set at a very small increment (in the order of $10^{-12} \mathrm{~s}$ ) during dwell and traverse stages to increase the accuracy. 


\subsection{Heat Generation From Pin Tool Nib}

In the current simulation, the pin tool nib was not modeled in order to avoid mesh locking due to incompressible plastic deformation. According to Schmidt et al. [13], the ratio between heat generated from pin nib and heat generated from tool shoulder is $16 \%$. Therefore, the heat generated from friction to the workpiece and plastic deformation in the model was multiplied by 1.16 as a compensation for the heat flow from pin tool nib.

\subsection{Material Properties}

The material properties of AA2219 are shown in Figs. 10, 11, and 12. Modulus of elasticity, thermal conductivity, and specific heat capacity are temperature-dependent properties and vary significantly with temperature. Conversely, workpiece density along with pin tool density, thermal conductivity, and specific heat capacity have been considered as temperature-independent properties and are listed in Table 4.

\subsection{Stress-strain Diagram}

Multilinear isotropic hardening with large strain and deformation capability has been used in the current analysis together with a strain rate-independent plasticity model. The true stress vs plastic strain at a strain rate of $\dot{\varepsilon}=1 \mathrm{~s}^{-1}$ for aluminum is shown in Fig. 13. The adopted temperature-dependent yield stresses were assumed to drop from a value of $350 \mathrm{MPa}$ at ambient temperature to $25 \mathrm{MPa}$ at a temperature of $370{ }^{\circ} \mathrm{C}$ according to the relationship, which can be seen in Fig. 14.

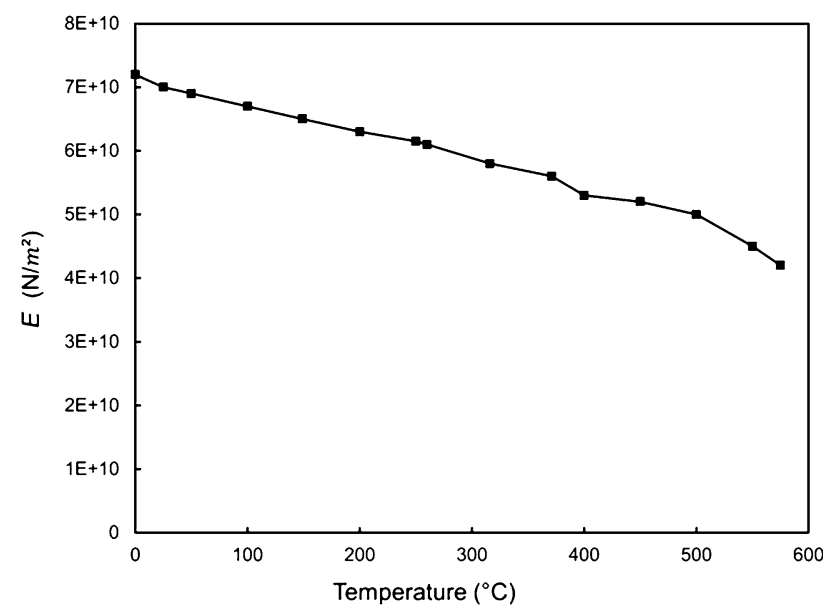

Fig. 10 Young's modulus of aluminum as a function of temperature [34]

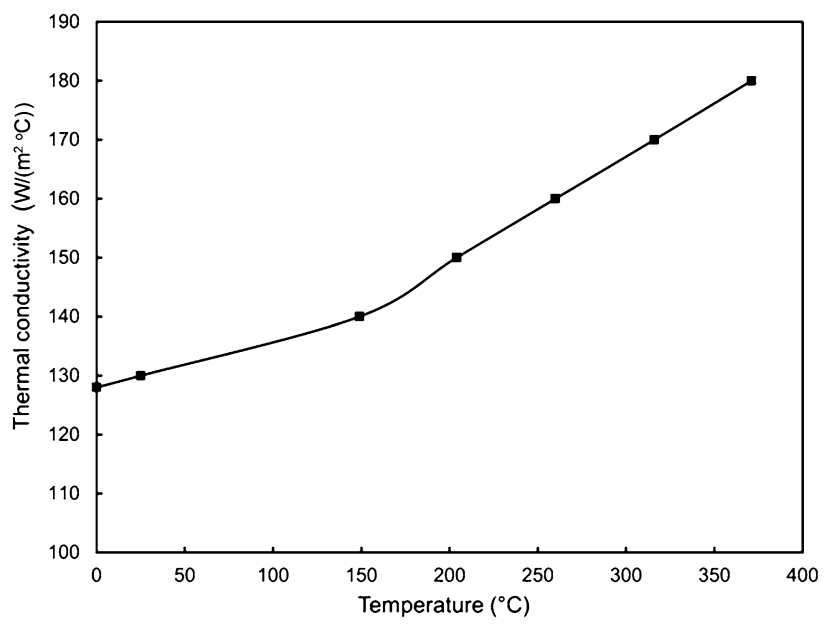

Fig. 11 Thermal conductivity of AA2219 as a function of temperature [35]

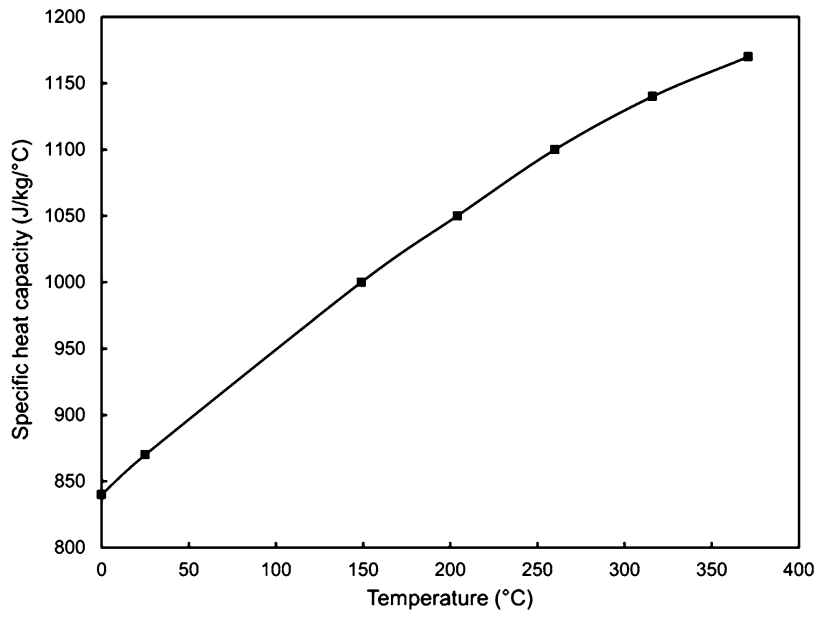

Fig. 12 Specific heat capacity of AA2219 as a function of temperature [35]

\subsection{Computational Time}

The thermomechanical analysis performed in ANSYS ${ }^{\circledR}$ used 20 Intel Ivy bridge $2.8 \mathrm{GHz}$ cores processor and $64 \mathrm{~GB}$ of RAM memory. The CPU time was about $30 \mathrm{~h}$ for $27 \mathrm{~s}$ of simulation. This simulation was done on a Supercomputer (SuperMIC, owned by Louisiana State University), which has a peak performance of 557 TeraFlop (TF).

\section{Thermal Verification}

Rather than comparing temperature history with a single weld schedule, three different weld schedules have been analyzed to show the robustness of the model. The three weld schedules chosen for that purpose have the same 
Table 4 Material properties used in the model [36]

\begin{tabular}{lllll}
\hline $\begin{array}{l}\text { Density of workpiece, } \\
\boldsymbol{\rho}\left(\mathrm{kg} / \mathrm{m}^{3}\right)\end{array}$ & $\begin{array}{l}\text { Density of tool, } \\
\boldsymbol{\rho}_{\mathbf{t}}\left(\mathrm{kg} / \mathrm{m}^{3}\right)\end{array}$ & $\begin{array}{l}\text { Thermal conductivity of the tool, } \\
\boldsymbol{k}_{\mathbf{t}}\left(\mathrm{W} / \mathrm{m}^{2}{ }^{\circ} \mathrm{C}\right)\end{array}$ & $\begin{array}{l}\text { Specific capacity of tool, } \boldsymbol{c}_{\mathbf{t}} \\
\left(\mathrm{J} / \mathrm{kg} /{ }^{\circ} \mathrm{C}\right)\end{array}$ & $\begin{array}{l}\text { Melting temperature of } \\
\text { workpiece }\left({ }^{\circ} \mathrm{C}\right)\end{array}$ \\
\hline 2840 & 24.4 & 460 & 543 \\
\hline
\end{tabular}

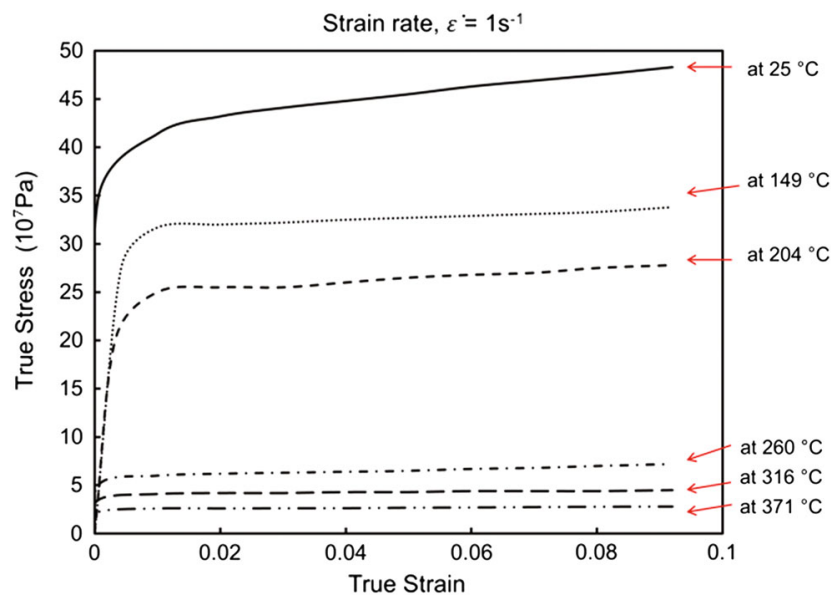

Fig. 13 True stress-strain diagram of the aluminum [30, 37]

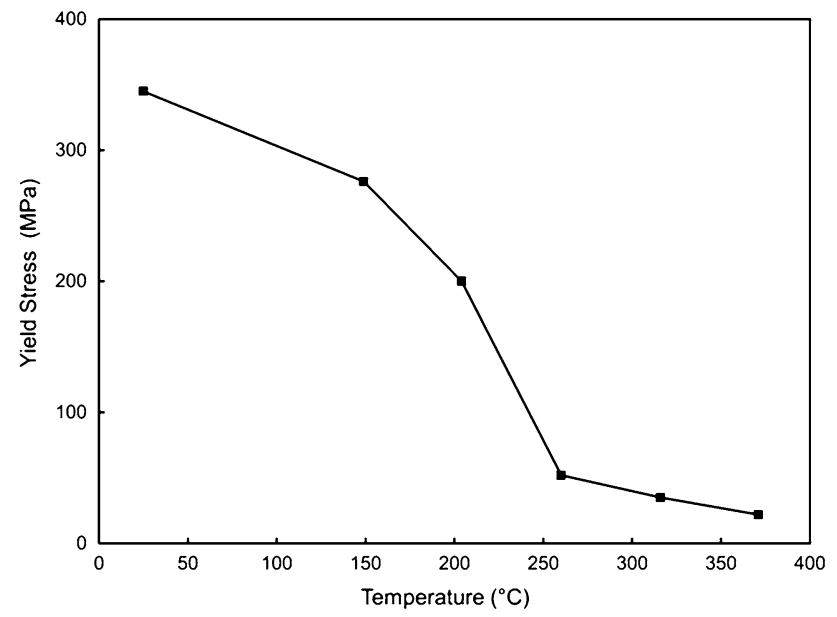

Fig. 14 Temperature-dependent yield stress of aluminum at $\dot{\varepsilon}=1 \mathrm{~s}^{-1}[30,37]$

rotational speed, the same travel speed, and the same temperature-dependent friction coefficient but different plunge force values. A summary of the weld schedules is listed in Table 5. Temperature generated during FSW experiment was measured using two different methods, namely attached thermocouple and thermographic device. The measured temperature results were compared with simulation results.

Figures 15, 16, and 17 show variations of temperature on the top surface of the workpiece at the thermocouple location of $y=42.36 \mathrm{~mm}, z=26 \mathrm{~mm}$ along the weld direction for the three different weld schedules. The comparison shows that FEA numerical results of temperature closely match with the experimental data.

Figures 18 and 19 represent temperature field and temperature profile, respectively, along the lateral direction from a simulation for a weld schedule with travel speed, $V$, equal to $1.27 \mathrm{~mm} / \mathrm{s}$, rotational speed, $\omega$, equal to $350 \mathrm{rpm}$, and a plunge force, $F_{z}$, equal to $15.568 \mathrm{kN}$. Figures 20, 21, and 22 represent comparison of the results obtained from FEA and from the experiment at transverse direction. From these figures, it can be seen that the temperature obtained from experiment is in close agreement with the simulated temperature. Error analyses between experimental temperature and FEA temperature have been shown in this section. Also, from Figs. 20, 21, 22, the temperature around the shoulder is higher than the surrounding area, which is contributed by friction mainly and by plastic deformation to a lesser extent [32]. For this localized heating up to the tool shoulder radius, temperature is the highest, and it decreases as the distance from center increases. Maximum temperatures obtained from the simulations or experiments in all three cases are 422, 431, and $462{ }^{\circ} \mathrm{C}$. In all cases, the maximum temperature is less than the melting temperature of AA2219 $\left(543{ }^{\circ} \mathrm{C}\right)$ and ranges between $77.7 \%$ and $84.5 \%$ of the melting temperature, which is typical for FSW.

The mean relative error is calculated between the experimental and the FEA analysis value as shown in Tables 6,7 , and 8 at different distances perpendicular to the weld.

For all schedules, the highest absolute relative error is below $6 \%$, and the average error for all cases is below $3.60 \%$.

\section{Energy Generation During FSW Process}

FSW causes heat generation to join workpieces together. During the FSW process, heat is generated through two possible ways, namely heat generation due to friction between tool/workpiece and heat generation due to plastic deformation. The aforementioned expressions in Eqs. (4) and Eq. (5) have been used to calculate plastic dissipation energy and friction energy dissipation converted to heat. 
Table 5 Different weld schedule for temperature verification

\begin{tabular}{llr}
\hline Rotational speed, $\boldsymbol{\omega}(\mathrm{rpm})$ & Travel speed, $V(\mathrm{~mm} / \mathrm{s})$ & Plunge force, $\boldsymbol{F}_{\boldsymbol{Z}}(\mathrm{kN})$ \\
\hline 350 & 1.27 & 12.455 \\
350 & 1.27 & 15.568 \\
350 & 1.27 & 21.351 \\
\hline
\end{tabular}

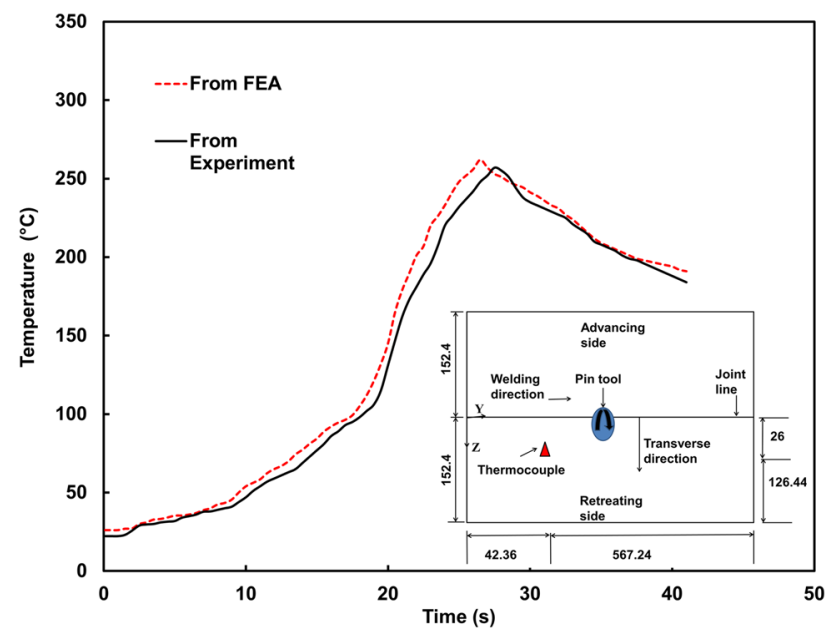

Fig. 15 Comparison between temperature histories of thermocouples and FEA results at $y=42.36 \mathrm{~mm}, \quad z=26 \mathrm{~mm}$ location $\left(V=1.27 \mathrm{~mm} / \mathrm{s} ; \omega=350 \mathrm{rpm} ; F_{z}=12.455 \mathrm{kN}\right)$

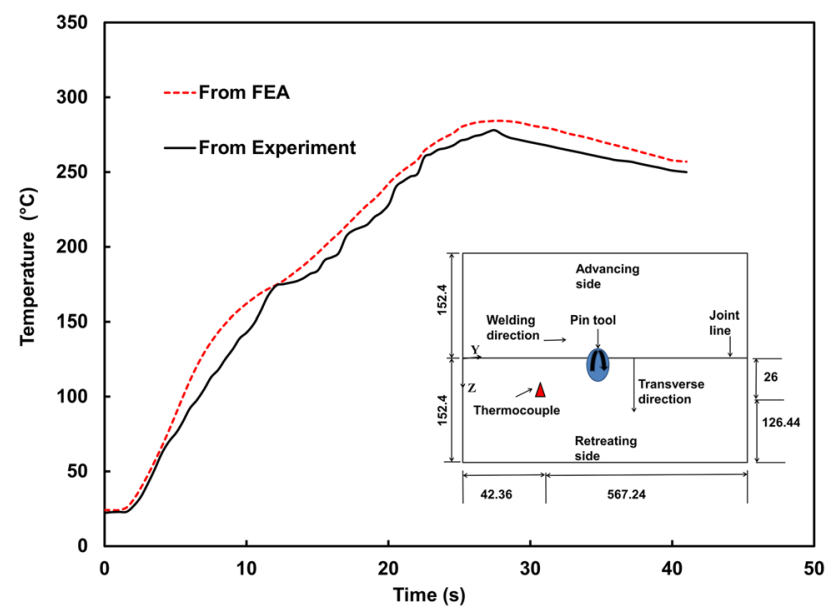

Fig. 16 Comparison between temperature histories of thermocouples and FEA results at $y=42.36 \mathrm{~mm}, z=26 \mathrm{~mm}$ location $\left(V=1.27 \mathrm{~mm} / \mathrm{s} ; \omega=350 \mathrm{rpm} ; F_{z}=15.568 \mathrm{kN}\right)$

From Table 9, plastic energy from our model was only responsible for $0.09 \%$ for a weld schedule with a plunge force of $21.351 \mathrm{kN}$, rotation speed of $350 \mathrm{rpm}$ and traverse speed of $1.27 \mathrm{~mm} / \mathrm{s}$. This percentage is low compared to values reported in the literature by previous researchers

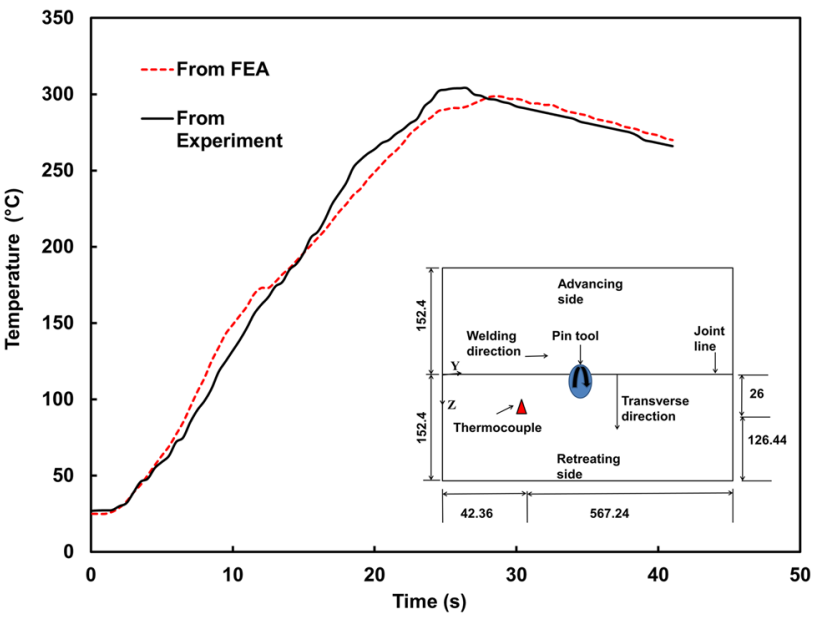

Fig. 17 Comparison between temperature histories of thermocouples and FEA results at $y=42.36 \mathrm{~mm}, z=26 \mathrm{~mm}$ location $\left(V=1.27 \mathrm{~mm} / \mathrm{s} ; \omega=350 \mathrm{rpm} ; F_{z}=21.351 \mathrm{kN}\right)$

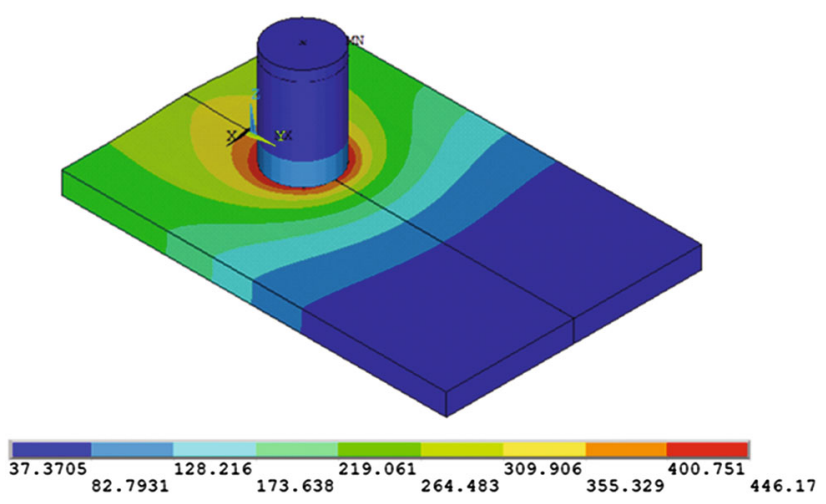

Fig. 18 Temperature field from simulation $(V=1.27 \mathrm{~mm} / \mathrm{s}$; $\omega=350 \mathrm{rpm} ; F_{z}=15.568 \mathrm{~N}$ )

such as Bastier et al. [32]. Bastier et al. [32] reported that plastic heat generation contributed only $4.4 \%$ of total heat generation of FSW aluminum alloy, with the remaining 95.6\% heat being generated by friction. The fact that the presented model cannot capture plastic heat generation accurately is mainly attributed to the fact that it only considers plastic deformations occurring at the top surface of the workpiece rather than around the weld nugget. This simplification in the current model implies an assumption 


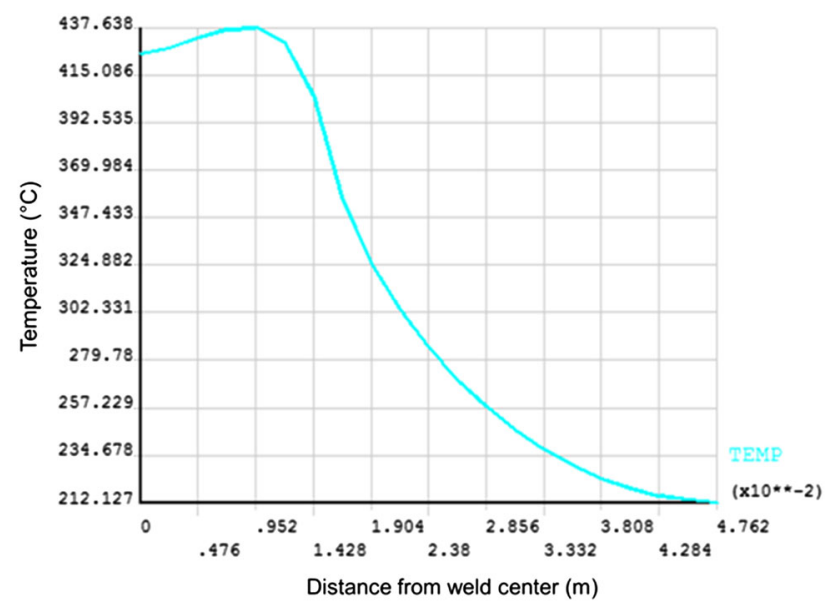

Fig. 19 Temperature variation from simulation along transverse direction $\left(V=1.27 \mathrm{~mm} / \mathrm{s} ; \omega=350 \mathrm{rpm} ; \mathrm{F}_{\mathrm{z}}=15.568 \mathrm{kN}\right)$

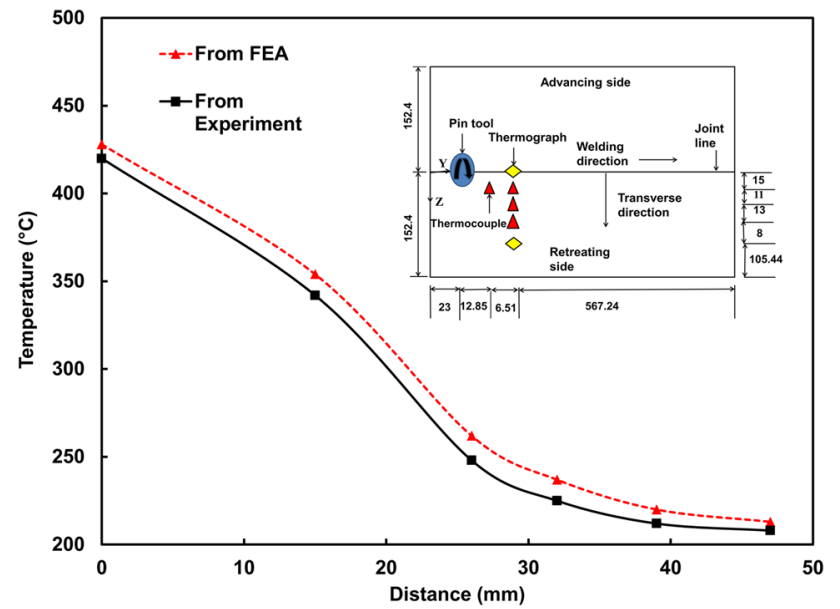

Fig. 20 Comparison of temperature variations between experimental and simulation data along transverse direction $(V=1.27 \mathrm{~mm} / \mathrm{s} ; \omega=$ $350 \mathrm{rpm} ; F_{z}=12.455 \mathrm{kN}$ )

that all heat is practically generated by friction, which should result in temperatures lower than the actual temperature by a few percentage points according to Bastier et al. [32]. While this is true for the results shown in Fig. 22 and most of the observed locations in Fig. 21, it is not the case for the weld schedule, whose results are presented in Fig. 20. This may be attributed to experimental reading errors that can surpass such a small difference of a few percentage points. The authors are presently working on developing an FSW model capable of accurately capturing the plastic deformation around the weld nugget, which requires modeling material flow in that area.

In the following sections, we will discuss the change friction energy, i.e., the dominant energy source, as a result of varying welds parameters. In the current work, heat generation due to friction is investigated to study the

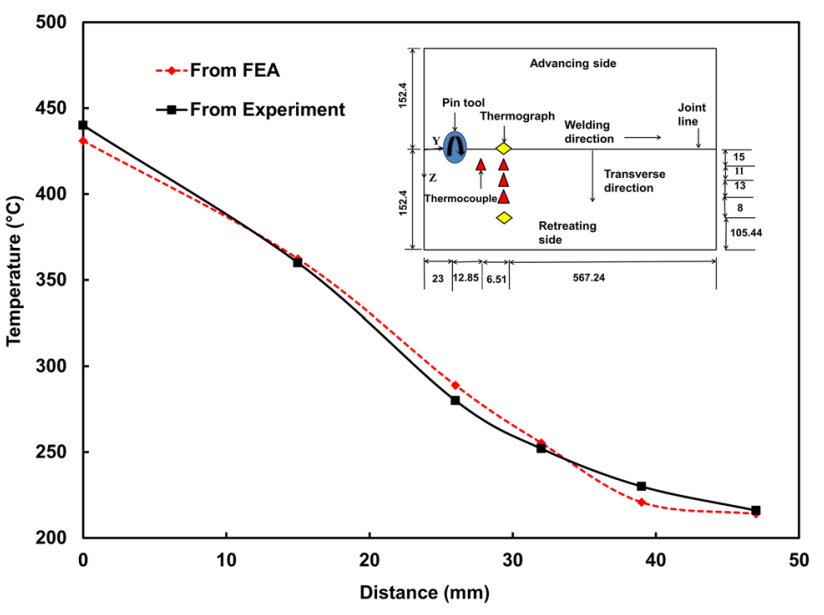

Fig. 21 Comparison of temperature variations between experimental and simulation data along transverse direction $(V=1.27 \mathrm{~mm} / \mathrm{s}$; $\omega=350 \mathrm{rpm} ; F_{z}=15.568 \mathrm{kN}$ )

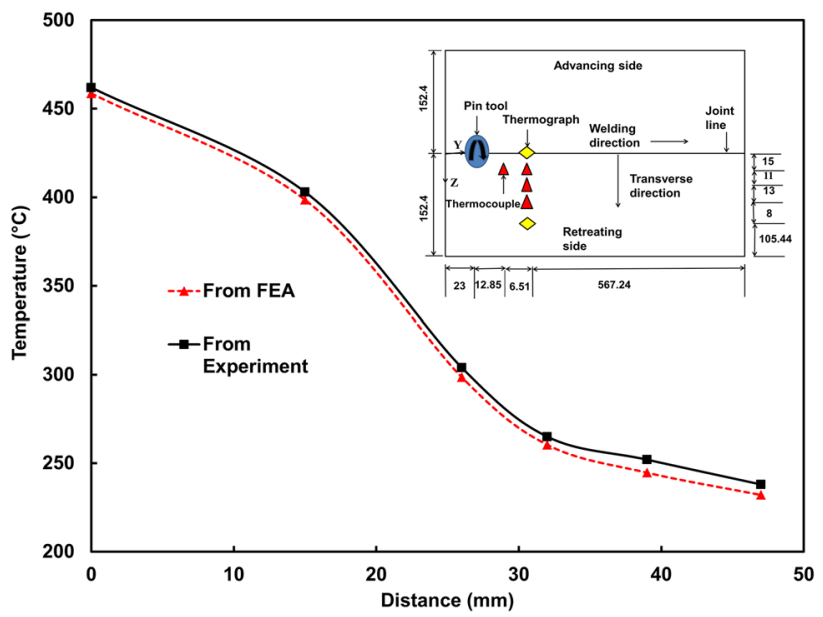

Fig. 22 Comparison of temperature variation between experimental and simulation data along transverse direction $(V=1.27 \mathrm{~mm} / \mathrm{s} ; \omega=$ $350 \mathrm{rpm} ; F_{z}=21.351 \mathrm{kN}$ )

effects of varying plunge force, rotational speed, and travel speed.

\subsection{Effect of Plunge Force on Welding}

A parametric study was conducted to investigate the effects of plunge force. Three different plunge forces of 12.455 , 15.568 , and $21.351 \mathrm{kN}$ were considered. During these analyses, travel speed and rotational speed were kept constant.

Figure 23 shows the frictional dissipation energy for $27 \mathrm{~s}$ of simulation for all three plunge force cases. It can be seen that the energy increases with the increase in plunge force. The total frictional dissipation energy increased $22.96 \%$ when plunge force is increased from 12.455 to 
Table 6 Error analysis for $F_{z}=12.455 \mathrm{kN}, \omega=350 \mathrm{rpm}, V=1.27 \mathrm{~mm} / \mathrm{s}$ weld schedule

\begin{tabular}{llll}
\hline Distance $(\mathrm{mm})$ & Temperature from FEA analysis $\left({ }^{\circ} \mathrm{C}\right)$ & Temperature from experiment $\left({ }^{\circ} \mathrm{C}\right)$ & Absolute error $(\%)$ \\
\hline 0 & 422 & 418 & 0.96 \\
15 & 354 & 342 & 3.51 \\
26 & 262 & 248 & 5.64 \\
32 & 237 & 225 & 5.30 \\
39 & 220 & 212 & 3.77 \\
47 & 213 & 208 & 2.40 \\
& & Average error & 3.60 \\
\hline
\end{tabular}

Table 7 Error analysis for $F_{z}=15.568 \mathrm{kN}, \omega=350 \mathrm{rpm}, V=1.27 \mathrm{~mm} / \mathrm{s}$ weld schedule

\begin{tabular}{llll}
\hline Distance $(\mathrm{mm})$ & Temperature from FEA analysis $\left({ }^{\circ} \mathrm{C}\right)$ & Temperature from experiment $\left({ }^{\circ} \mathrm{C}\right)$ & Absolute error $(\%)$ \\
\hline 0 & 431.0 & 440 & 2.04 \\
15 & 362.3 & 360 & 0.64 \\
26 & 288.9 & 280 & 3.18 \\
32 & 255.3 & 252 & 1.31 \\
39 & 220.8 & 230 & 4.00 \\
47 & 214.0 & 216 & 0.93 \\
& & Average error & 2.02 \\
\hline
\end{tabular}

Table 8 Error analysis for $F_{z}=21.351 \mathrm{kN}, \omega=350 \mathrm{rpm}, V=1.27 \mathrm{~mm} / \mathrm{s}$ weld schedule

\begin{tabular}{llll}
\hline Distance $(\mathrm{mm})$ & Temperature from FEA analysis $\left({ }^{\circ} \mathrm{C}\right)$ & Temperature from experiment $\left({ }^{\circ} \mathrm{C}\right)$ & Absolute error $(\%)$ \\
\hline 0 & 458.66 & 462 & 0.72 \\
15 & 398.56 & 403 & 1.10 \\
26 & 298.56 & 304 & 1.79 \\
32 & 260.4 & 265 & 1.73 \\
39 & 244.65 & 252 & 2.91 \\
47 & 232.04 & 238 & 2.50 \\
& & Average error & 1.79 \\
\hline
\end{tabular}

Table 9 Friction and plastic dissipation energy for weld schedule plunge force $21.351 \mathrm{kN}$, rotation rate $350 \mathrm{rpm}$, and traverse speed $1.27 \mathrm{~mm} / \mathrm{s}$

\begin{tabular}{llllll}
\hline Rotational speed, $\boldsymbol{\omega}(\mathrm{rpm})$ & Traverse speed, $V(\mathrm{~mm} / \mathrm{s})$ & Plunge force, $\boldsymbol{F}_{\boldsymbol{Z}}(\mathrm{kN})$ & Frictional energy $(\mathrm{J})$ & Plastic energy $(\mathrm{J})$ & Total energy $(\mathrm{J})$ \\
\hline 350 & 1.27 & 21.351 & $1.35 \times 10^{6}$ & $1.25 \times 10^{3}$ & $1.35125 \times 10^{6}$
\end{tabular}

$21.351 \mathrm{kN}$. Similarly, frictional dissipation energy increased $21.48 \%$ when plunge force is increased from 15.568 to $21.351 \mathrm{kN}$. A higher plunge force causes more material to penetrate and spin by rotation and thus produces more energy. Table 10 summarizes the plunge force effect on the frictional energy. This result is consistent with the experimental result reported by Tang et al. [38].

\subsection{Effect of Spindle Rotational Speed}

Three different welding tool rotational speeds of 200, 300, and $450 \mathrm{rpm}$ have been considered to study the effect of the tool's rotational speed. A constant ravel speed, $V=2.539 \mathrm{~mm} / \mathrm{s}$, and a constant plunge force, $F_{z}=26.68$ $\mathrm{kN}$, have been used in the analysis. 


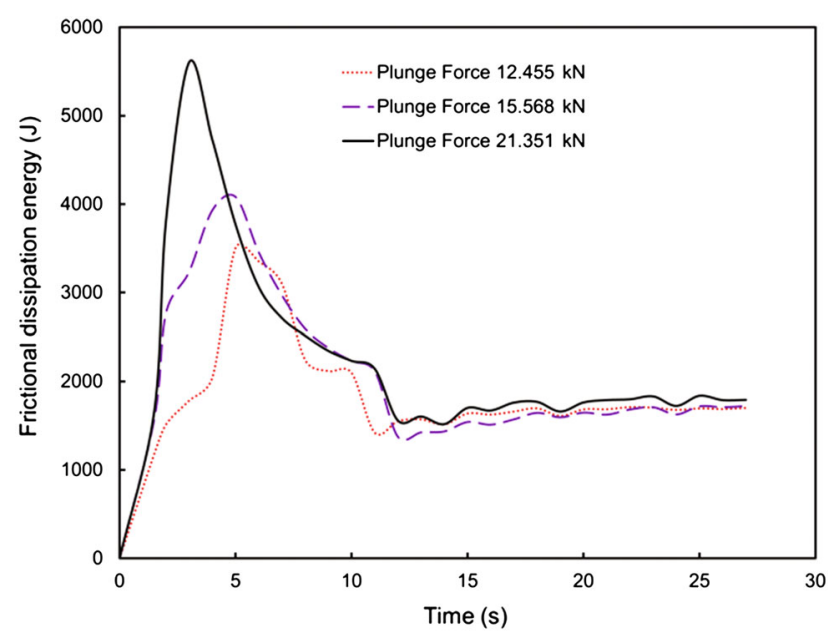

Fig. 23 Frictional dissipation energy variation with plunge force $(\omega=350 \mathrm{rpm}, v=1.27 \mathrm{~mm} / \mathrm{s})$

Figure 24 represents frictional dissipation energy at 200, 300 , and $450 \mathrm{rpm}$, respectively. The higher rotational speed produced higher dissipation energy. The total frictional dissipation energy increased about $80.06 \%$ when rotational speed is increased from 200 to $450 \mathrm{rpm}$. Moreover, when the rotational speed is increased from 300 to $450 \mathrm{rpm}$, total frictional energy increased about $32.25 \%$. This higher energy is produced by higher relative velocity of the materials due to high rotational speed. Table 11 summarizes the effect of rotational speed on frictional dissipation energy. Similar results have been reported by the experimental work of Tang et al. [38].

\subsection{Effect of Welding Speed}

The effect of tool travel speed on frictional dissipation energies was also investigated by considering three different weld speeds $3.386,2.539$, and $1.693 \mathrm{~mm} / \mathrm{s}$. A constant rotational speed, $\omega=300 \mathrm{rpm}$, and a constant plunge force, $F_{z}=26.68 \mathrm{kN}$, have been used in these analyses.

From Fig. 25, it can be seen that as the welding speed decreases, frictional dissipation energy increases. The

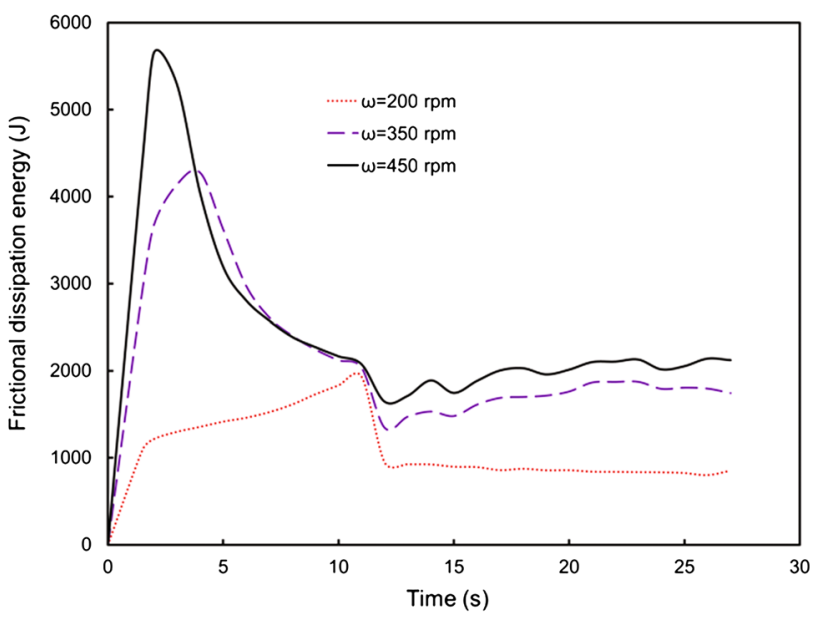

Fig. 24 Frictional dissipation energy variation with rotational speed $\left(v=1.27 \mathrm{~mm} / \mathrm{s}, F_{z}=26.68 \mathrm{kN}\right)$

total frictional dissipation energy increased about 5.40\% when travel speed is decreased from 3.386 to $1.693 \mathrm{~mm} / \mathrm{s}$. Moreover, total frictional dissipation energy increased about $4.50 \%$ when the travel speed is decreased from 2.539 to $1.693 \mathrm{~mm} / \mathrm{s}$. The lower travel speed of the tool results in more time to rotate on material, and thus, the rate by which heat is produced locally increases. Table 12 summarizes the effect of travel speed on frictional dissipation energy.

\section{Conclusions}

A fully coupled thermomechanical 3D model has been developed to analyze thermal heat generation and distribution during FSW. The goal of this research effort is to advance FSW modeling a degree closer to actual weld conditions by introducing sticking and sliding friction along with temperature-dependent friction coefficient to study the heat generation during FSW process. Though the developed model cannot capture plastic deformation accurately, it is an improvement over thermal model as it

Table 10 Summary of friction dissipation energies for various plunge forces

\begin{tabular}{lllll}
\hline Rotational speed, $\boldsymbol{\omega}(\mathrm{rpm})$ & Traverse speed, $V(\mathrm{~mm} / \mathrm{s})$ & Plunge force, $\boldsymbol{F}_{\boldsymbol{Z}},(\mathrm{kN})$ & Frictional energy $(\mathrm{J})^{\text {Frictional energy percentage increase }^{\mathrm{a}}}$ \\
\hline 350 & 1.27 & 12.455 & $1.04 \times 10^{6}$ & $22.96 \%$ \\
350 & 1.27 & 15.568 & $1.06 \times 10^{6}$ & $21.48 \%$ \\
350 & 1.27 & 21.351 & $1.35 \times 10^{6}$ & Base 1 \\
\hline
\end{tabular}

\footnotetext{
${ }^{\text {a }}$ With respect to Base1 weld schedule
} 
Table 11 Summary of friction dissipation energies for various rotational speeds

\begin{tabular}{lllll}
\hline $\begin{array}{l}\text { Rotational speed, } \boldsymbol{\omega}, \\
(\mathrm{rpm})\end{array}$ & $\begin{array}{l}\text { Traverse speed, } V(\mathrm{~mm} / \\
\mathrm{s})\end{array}$ & $\begin{array}{l}\text { Plunge force, } \boldsymbol{F}_{\boldsymbol{Z}}, \\
(\mathrm{kN})\end{array}$ & $\begin{array}{l}\text { Total frictional energy } \\
(\mathrm{J})\end{array}$ & $\begin{array}{l}\text { Frictional energy percentage } \\
\text { increase }^{\mathrm{a}}\end{array}$ \\
\hline 200 & 2.539 & 26.68 & $3.09 \times 10^{5}$ & $80.06 \%$ \\
300 & 2.539 & 26.68 & $1.05 \times 10^{6}$ & $32.25 \%$ \\
450 & 2.539 & 26.68 & $1.55 \times 10^{6}$ & Base2 \\
\hline
\end{tabular}

${ }^{a}$ With respect to Base2 weld schedule

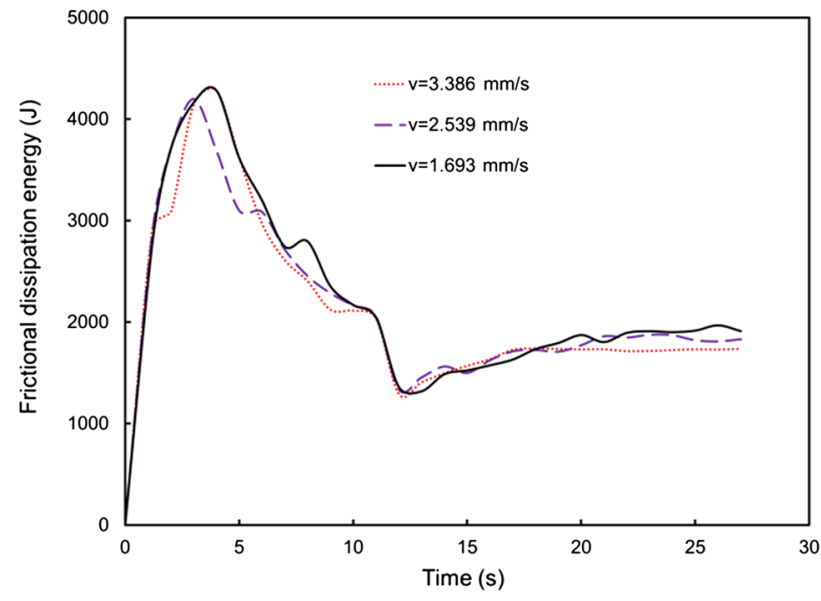

Fig. 25 Frictional dissipation energy variation with welding speed $\left(F_{z}=26.68 \mathrm{kN}, \omega=300 \mathrm{rpm}\right)$

Table 12 Summary of total friction and plastic dissipation energies for various travel speed

\begin{tabular}{lllll}
\hline $\begin{array}{l}\text { Rotational } \\
\text { speed, } \boldsymbol{\omega}, \\
(\mathrm{rpm})\end{array}$ & $\begin{array}{l}\text { Travel } \\
\text { speed, } \\
V(\mathrm{~mm} / \mathrm{s})\end{array}$ & $\begin{array}{l}\text { Plunge } \\
\text { force, } \boldsymbol{F}_{\boldsymbol{Z}}, \\
(\mathrm{kN})\end{array}$ & $\begin{array}{l}\text { Total } \\
\text { frictional } \\
\text { energy }(\mathrm{J})\end{array}$ & $\begin{array}{l}\text { Frictional } \\
\text { energy } \\
\text { percentage } \\
\text { increase }^{\mathrm{a}}\end{array}$ \\
\hline 300 & 3.386 & 26.68 & $1.05 \times 10^{6}$ & $5.40 \%$ \\
300 & 2.539 & 26.68 & $1.06 \times 10^{6}$ & $4.50 \%$ \\
300 & 1.693 & 26.68 & $1.11 \times 10^{6}$ & Base3 \\
\hline
\end{tabular}

${ }^{\text {a }}$ With respect to Base 3 weld schedule

captures heat generation due to friction. The following conclusions can be drawn from this research:

(1) The temperature profile obtained from simulation is consistent with the temperature profile obtained from experiments. Temperature profiles from three different weld schedules have been used to compare the result with the simulation results. In all cases, the highest relative error is below $6 \%$ with a mean value of $2.47 \%$.

(2) Even though the current model does not capture all of the plastic energy produced by FSW in the workpiece, its results are in good agreement with experimentally measured temperatures. This implies that heat produced from the frictional work of the tool and workpiece produces most of the energy, which is consistent with similar findings in the literature [19].

(3) A parametric study was conducted to analyze the effect of different weld parameters-plunge force, rotational speed, and travel speed. Findings from this study revealed that:

(a) The higher the plunge force, the higher the friction dissipation energy generated. Total frictional dissipation energy is increased by 23 and $21 \%$ when plunge force is increased from 12.455 to $21.351 \mathrm{kN}$.

(b) The higher the rotational speed, the higher the total amount of frictional dissipation energy. When rotational speed is increased from 200 to $450 \mathrm{rpm}$, total frictional energy is increased to $80.06 \%$ and $32.25 \%$, respectively.

(c) Lower travel speed causes more total frictional and plastic dissipation energy. When travel speed changes from 3.386 to $1.693 \mathrm{~mm} / \mathrm{s}$, the total frictional is changed from $5.40 \%$ and $4.50 \%$, respectively.

(4) Among the three major FSW process parameters, the effect of rotational speed on generating frictional energy is found to be the most important parameter.

Acknowledgments The authors gratefully acknowledge the financial support received from the Louisiana Economic Development Assistantship (EDA) program. Authors are grateful to Mr. G. Verma, senior technology specialist at ANSYS ${ }^{\circledR}$ for his technical support. Authors are thankful to LSU's High Performance Computing Services for their support and assistance with the modeling part of this study.

\section{References}

[1] W.M. Thomas, E.D. Nicholas, J.C. Needham, M.G. Murch, P. Templesmith, C.J. Dawes, GB Patent Application No. 9,125,978.8, Dec 1991

[2] Z. Feng, X.L. Wang, S.A. David, P.S. Sklad, Sci. Technol. Weld. Join. 12, 348 (2007) 
[3] X.K. Zhu, Y.J. Chao, J. Mater. Process. Technol. 146, 263 (2004)

[4] M.Z.H. Khandkar, J.A. Khan, A.P. Reynolds, Sci. Technol. Weld. Join. 8, 165 (2003)

[5] P. Prasanna, B.S. Rao, G.K.M. Rao, Int. J. Adv. Manuf. Technol. 51, 925 (2010)

[6] R. Nandan, G.G. Roy, T. Debroy, Metall. Mater. Trans. A 37, 1247 (2006)

[7] P.A. Colegrove, H.R. Shercliff, Sci. Technol. Weld. Join. 11, 429 (2006)

[8] P. Ulysse, Int. J. Mach. Tools Manuf. 42, 1549 (2002)

[9] E. Ranjbarnodeh, S. Hanke, S. Weiss, A. Fischer, Int. J. Miner. Metall. Mater. 19, 923 (2012)

[10] Y.H. Yau, A. Hussain, R.K. Lalwani, H.K. Chan, N. Hakimi, Int. J. Miner. Metall. Mater. 20, 779 (2013)

[11] S.D. Jai, Y.Y. Jin, Y.M. Yue, S.S. Gao, Y.X. Huang, J. Mater. Sci. Technol. 29, 955 (2013)

[12] H.B. Schmidt, J.H. Hattel, Scr. Mater. 58, 332 (2008)

[13] H. Schmidt, J. Hattel, J. Wert, Model. Simul. Mater. Sci. Eng. 12, 143 (2004)

[14] M. Song, R. Kovacevic, Int. J. Mach. Tools Manuf. 43, 605 (2003)

[15] C. Chen, R. Kovacevic, Proc. Inst. Mech. Eng. Part C J. Eng. Mech. Eng. Sci. 218, 509 (2004)

[16] X.X. Zhang, B.L. Xiao, Z.Y. Ma, Metall. Mater. Trans. A 42, $3218(2011)$

[17] X.X. Zhang, B.L. Xiao, Z.Y. Ma, Metall. Mater. Trans. A 42, 3229 (2011)

[18] G. Buffa, J. Hua, R. Shivpuri, L. Fratini, Mater. Sci. Eng. A 419, 389 (2006)

[19] Z. Zhang, H.W. Zhang, Sci. Technol. Weld. Join. 12, 226 (2007)

[20] Z. Zhang, H.W. Zhang, Mater. Des. 30, 900 (2009)

[21] H.W. Zhang, Z. Zhang, J.T. Chen, J. Mater. Process. Technol. 183, 62 (2007)

[22] D. Wang, B.L. Xiao, D.R. Ni, Z.Y. Ma, Acta Metall. Sin. (Engl. Lett.) 27, 816 (2014)
[23] A.H. Feng, D.L. Chen, Z.Y. Ma, W.Y. Ma, R.J. Song, Acta Metall. Sin. (Engl. Lett.) 27, 723 (2014)

[24] W.F. Xu, J.H. Liu, D.L. Chen, J. Mater. Sci. Technol. 31, 953 (2015)

[25] R.Z. Xu, D.R. Ni, Q. Yang, C.Z. Liu, Z.Y. Ma, J. Mater. Sci. Technol. 32, 76 (2016)

[26] M.W. Dewan, D.J. Hugget, T.W. Liao, M.A. Wahab, A.M. Okeil, Mater. Des. 92, 288 (2016)

[27] Ansys Inc., ANSYS Mechanical APDL Theory Reference, 2013, http://148.204.81.206/Ansys/150/ANSYSMechanicalTheoryRef erence.pdf. Accessed on 28 Aug 2015

[28] A.P. Reynolds, T. Seidel, S. Xu, in Proceedings Joining of Advanced and Specialty Materials, ASM International, St. Louis, Missouri, 9-12 Oct, 2000

[29] Y.J. Chao, X. Qi, W. Tang, Trans. ASME 125, 138 (2003)

[30] M. Awang, Dissertation, West Virginia University, 2007

[31] R.S. Mishra, Z.Y. Ma, Mater. Sci. Eng. R 50, 1 (2005)

[32] A. Bastier, M.H. Maitournam, K. Dang, F. Roger, Sci. Technol. Weld. Join. 11, 278 (2006)

[33] Ansys Inc., Theory Reference for the Mechanical APDL and Mechanical Applications, 2009, http://orange.engr.ucdavis.edu/ Documentation12.0/120/ans_thry.pdf. Accessed on 2 Aug 2015

[34] R.B. McLellan, T. Ishikawa, J. Phys. Chem. Solids 48, 603 (1987)

[35] H.J. Zhang, H.J. Liu, L. Yu, Trans. Nonferrous Met. Soc. China 23, 1114 (2013)

[36] ASM International Handbook Committee, Properties and Selection: Nonferrous Alloys and Special-Purpose Materials (ASM Handbook, ASM International, Materials park, OH 1990), p. 65

[37] E. Semb, Dissertation, Behavior of Aluminum at Elevated Strain Rates and temperatures, Norwegian University of Science and Technology, 2013

[38] X.G.W. Tang, J.C. Mc Clure, L.E. Murr, A. Nunes, J. Mater. Process. Manuf. Sci. 163, 7 (1998) 